\title{
ARTICLE
}

Clinical Research

\section{Hormone therapy use and the risk of acute kidney injury in patients with prostate cancer: a population-based cohort study}

\author{
Chris R. Cardwell $\mathbb{1}^{1} \cdot$ Joe M. O'Sullivan $\mathbb{1}^{2,3} \cdot$ Suneil Jain ${ }^{2,3} \cdot$ Blánaid M. Hicks ${ }^{1} \cdot$ Paul A. Devine $\mathbb{C}^{4} \cdot$ \\ Úna C. McMenamin ${ }^{1}$
}

Received: 2 December 2020 / Revised: 8 February 2021 / Accepted: 8 March 2021 / Published online: 26 March 2021

(c) The Author(s) 2021. This article is published with open access

\begin{abstract}
Background Hormone therapy is widely used in prostate cancer. However, studies have raised concerns that hormone therapy, particularly the use of gonadotropin-releasing hormone agonists, could increase the risk of acute kidney injury. Methods Men newly diagnosed with non-metastatic prostate cancer, from 2012 to 2017, were identified from the Scottish Cancer Registry. A matched comparison cohort of prostate cancer-free men was also identified. Hormone therapy use was determined from the Prescribing Information System in Scotland. The primary outcome was hospitalisations with acute kidney injury taken from Scottish hospital records (SMR01) up to June 2019. Time-dependent Cox regression models were used to calculate hazard ratios (HRs) and 95\% confidence intervals (CIs) for acute kidney injury by hormone therapy use. Results The prostate cancer cohort contained 10,751 patients followed for 41,997 person years, during which there were 618 hospitalisations with acute kidney injury. Prostate cancer patients had higher rates of acute kidney injury compared with cancer-free controls (adjusted HR $=1.47$ 95\% CI 1.29, 1.69). However, prostate cancer patients currently using hormone therapy (adjusted HR $=1.1495 \%$ CI 0.92, 1.41), including gonadotropin-releasing hormone $(\mathrm{GnRH})$ agonists (adjusted $\mathrm{HR}=1.1395 \%$ CI $0.90,1.40$ ), did not appear to have a marked increase in acute kidney injury compared with prostate cancer patients not using hormone therapy after adjusting for potential confounders.

Conclusions In our cohort, there was little evidence that gonadotropin-releasing hormone agonists were associated with marked increases in acute kidney injury.
\end{abstract}

\section{Introduction}

Androgen deprivation therapy was initially used for advanced prostate cancer [1] but is increasingly being used in more localised disease [2,3]. However, the marked reductions in testosterone, caused by androgen deprivation

Chris R. Cardwell

c.cardwell@qub.ac.uk

1 Centre for Public Health, Queen's University Belfast, Belfast, Northern Ireland, UK

2 Centre for Cancer Research and Cell Biology, Queen's University Belfast, Belfast, Northern Ireland, UK

3 Radiotherapy Department, Cancer Centre, Belfast City Hospital, Belfast, Northern Ireland, UK

4 Regional Nephrology and Transplant Unit, Belfast City Hospital, Belfast, UK therapy, are associated with various side effects including fractures, diabetes and cardiovascular disease [4].

Recently concerns have been raised that androgen deprivation therapy could also increase the risk of acute kidney injury. Various potential mechanisms have been proposed [5, 6]. For instance, androgen deprivation therapy increases dyslipidemia and hyperglycemia which may disrupt glomerular function [7]. Androgen deprivation therapy reduces testosterone and testosterone may directly protect vasodilation of renal vessels [8]. In addition, androgen deprivation therapy may increase the risk of various cardiovascular disease, which along with treatments for cardiovascular disease, could increase acute kidney injury risk $[9,10]$. To date, only two studies $[5,6]$ have investigated hormone therapy use and acute kidney injury in humans. A UK study [5] observed a large (150\% increase) in acute kidney injury with current hormone therapy use whilst a US study [6] observed a comparatively small $24 \%$ increase with any use of gonadotropin-releasing hormone $(\mathrm{GnRH})$ agonists. Further research is warranted not only because the 
magnitude of associations was so markedly different in these studies but also because these studies had weaknesses (for instance, one [5] could not adjust for cancer stage whilst the other [6] could not determine dose or duration of androgen deprivation therapy use).

Therefore, we investigated the association between hormone therapy use and acute kidney injury in a contemporary population-based prostate cancer cohort from Scotland.

\section{Subjects and methods}

\section{Data sources}

The following linked databases were utilised [11]: the Scottish Cancer Registry; the Scottish National Prescribing Information System (PIS), which captures all community dispensed medications in Scotland; the General/Acute Inpatient and Day Case dataset (SMR01), which captures hospital diagnoses and operations and has high accuracy for various diagnoses [12]; the Outpatient Attendance dataset (SMR00), which captures diagnoses and procedures from outpatient clinics; and, the National Records of Scotland Death Records which captures date and cause of death. These databases covered Scotland from January 1999 to June 2019, apart from the PIS which was available from January 2009 to June 2019. Linkages between data sources were conducted using the Community Health Index number [11]. The study was approved by the Privacy Advisory Committee of the National Health Service National Services Scotland (number: 1617-0374).

\section{Study design}

A cohort of men newly diagnosed with non-metastatic (M stage 0) prostate cancer (ICD10, International Classification of Diseases 10th revision, code C61) between January 2012 and December 2017, was identified from the Scottish Cancer Registry. Patients were excluded if they: had a previous cancer diagnosis (apart from non-melanoma skin cancer or in situ tumours); had inconsistent dates (specifically a record of hormone therapy or radical prostatectomy more than 6 months before cancer diagnosis); or, had a renal disease diagnosis (including acute kidney injury, defined later, or chronic kidney disease, based upon ICD10 codes [13]) prior to prostate cancer diagnosis.

A separate cohort of cancer-free controls was also selected. One population-based control was randomly selected, without replacement, using the Community Health Index database, matched on year of birth to each patient with prostate cancer. The index date in the controls was defined as the date of prostate cancer diagnosis in their matched case.
The primary outcome was hospitalisation for acute kidney injury identified by the ICD10 code of $\mathrm{N} 17$ as the main or secondary condition, as previously defined $[5,14]$, in SMR01. Thus, prostate cancer patients were followed from the date of prostate cancer diagnosis (and controls were followed from the index date) to the earliest of the date of first acute kidney injury, date of death, date of leaving Scotland or June 2019.

\section{Exposure}

Hormone therapy consisted of GnRH agonists (including goserelin, leuprorelin, triptorelin and histrelin), the GnRH antagonist degarelix, oral anti-androgens (including bicalutamide, enzalutamide, flutamide and cyproterone acetate), estrogens and orchidectomy. Medical hormone therapy was identified from dispensed medications from the PIS. The pack size and strength were used to calculate days of use based upon the daily defined doses (DDDs) from the World Health Organisation[15]. The Scottish Cancer Registry provided data on initial curative radiotherapy. Orchidectomy (ICD10 codes N051, N052, N061 and N063 [16]) and radical prostatectomy (ICD10 code M61[16]) were taken from SMR01.

\section{Confounders}

The Scottish Cancer Registry provided Gleason score and stage (based upon pathological stage, where recorded, or clinical stage). Comorbidities from the Charlson comorbidity index (specifically acute myocardial infarction, congestive heart failure, peripheral vascular disease, cerebrovascular accident, pulmonary disease, connective tissue disorder, peptic ulcer, liver disease, diabetes, diabetes complications, paraplegia, renal disease and severe liver disease, using previous ICD codes [13]) were identified before cancer diagnosis from hospital admissions data (SMR00 and SMR01). The following medications were determined from PIS records in the year prior to diagnosis: non-steroidal anti-inflammatory drugs, aspirin, beta-blockers, angiotensin-converting enzyme inhibitors, angiotensin II receptor blockers (ARBs), diuretics, statins, warfarin, digoxin, clopidogrel, dipyridamole, nitrates, insulin, sulfonylureas, metformin, tamsulosin and other diabetic medications. Deprivation level was determined from the postcode of residence using the 2009 Scottish Index of Multiple Deprivation [17].

\section{Statistical analysis}

An initial analysis was conducted comparing acute kidney injury in prostate cancer patients to all population-based controls using Cox regression models to calculate hazard 


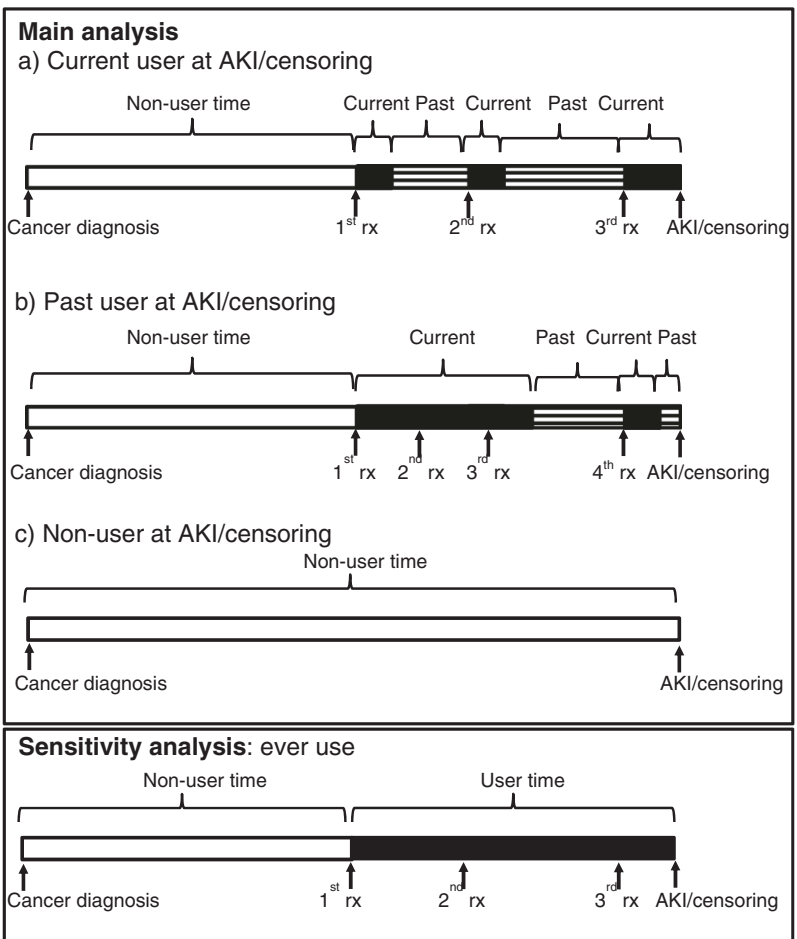

Fig. 1 Figure illustrating the study design. Exposure categories are shown for the main analysis in the top panel (including current (a), past (b) and non-users (c)) and for the senstivity analysis in the lower panel.

ratios (HRs) and 95\% confidence intervals (CIs) adjusting for age, deprivation, comorbidities (stated above) and other medications (stated above).

In prostate cancer patients, current use of hormone therapy was modelled as a time-varying covariate. Patients became a user upon the date of each hormone therapy prescription, and remained a user for the duration of the prescription, based upon the daily defined dose, plus a residual effect. The duration of the residual effect was taken from a previous study [5] and was 3 months for $\mathrm{GnRH}$ agonists and antagonists and 1 month for antiandrogens and estrogens. The exposure period from the end of one prescription to the start of the next was allocated to past use. A diagram explaining the study design is shown in Fig. 1. Patients receiving orchidectomy were considered exposed from the date of orchidectomy until the end of follow-up. Cox regression models were then used to calculate HRs and 95\% CI for acute kidney injury comparing hormone therapy current use and past use to non-users. The main model contained year of diagnosis, age, deprivation, cancer treatment (radiotherapy and radical prostatectomy as time-varying covariates), comorbidities (stated above, in the year prior to diagnosis) and other medications (stated above, in the year prior to diagnosis). Separate analyses were conducted additionally adjusting for $\mathrm{T}$ stage and $\mathrm{N}$ stage, including those with stage $\mathrm{X}$ [unstaged or stage unknown] as a separate category (corresponding to $3 \%$ and $6 \%$, respectively). Analyses were repeated separately for GnRH agonists, the $\mathrm{GnRH}$ antagonist degarelix and either GnRH agonists or antagonists.

Additional analyses were conducted. First, analyses were repeated using the outcome of acute kidney injury based solely upon the main condition within hospital records. Second, analysis was repeated using the outcome of hospitalisation or death from acute kidney injury. Third, analyses were conducted introducing a lag of 90 days. Fourth, analyses were repeated assuming a 1year residual effect for $\mathrm{GnRH}$ agonists and analyses were repeating halving all residual effects to 45 days for $\mathrm{GnRH}$ agonists and antagonists and 15 days for anti-androgens and estrogens. Fifth, analyses were repeated in patients with $\mathrm{M}$ stage 0 or $\mathrm{X}$ and separate analysis was repeated including all prostate cancer patients. Sixth, an analysis was conducted restricted to patients with localised prostate cancer ( $\mathrm{T}$ stage 1 or $2, \mathrm{~N}$ stage 0 and $\mathrm{M}$ stage 0 ). Seventh, analyses were repeated censoring individuals on date of radical prostatectomy and/or radiotherapy. Eighth, the analysis was repeated not adjusting for radical prostatectomy and radiotherapy, to avoid the risk of adjusting for an intermediate on the causal pathway[18]. Ninth, an analysis was conducted additionally adjusting for Gleason score, overall and in patients with localised prostate cancer.

Finally, an analysis was conducted based upon any use of hormone therapy with individuals considered users from first use until the end of follow-up. A similar exposureresponse analysis was conducted with patients deemed nonusers before first use, a short-term user from this time to 365 days of use (based upon DDDs), and a long-term user from then on. All analyses were conducted using STATA 16 (StataCorp, College Station, TX, USA) and STATA code is available (upon request).

\section{Results}

Figure 2 shows the patient selection. Overall, 10,751 patients with non-metastatic prostate cancer were followed for 41,997 person years in whom there were 618 hospitalisations with acute kidney injury (15 per 1000 person years).

In total 10,313 population-based controls were identified, including 485 hospitalisations with acute kidney injury, corresponding to a $47 \%$ increase in acute kidney injury in non-metastatic prostate cancer patients compared with controls (HR $=1.47,95 \%$ CI: $1.29,1.69$ after adjustment for age, deprivation, medication use and comorbidities). 
Fig. 2 Flow diagram of selection of prostate cancer patients and matched cancerfree controls.

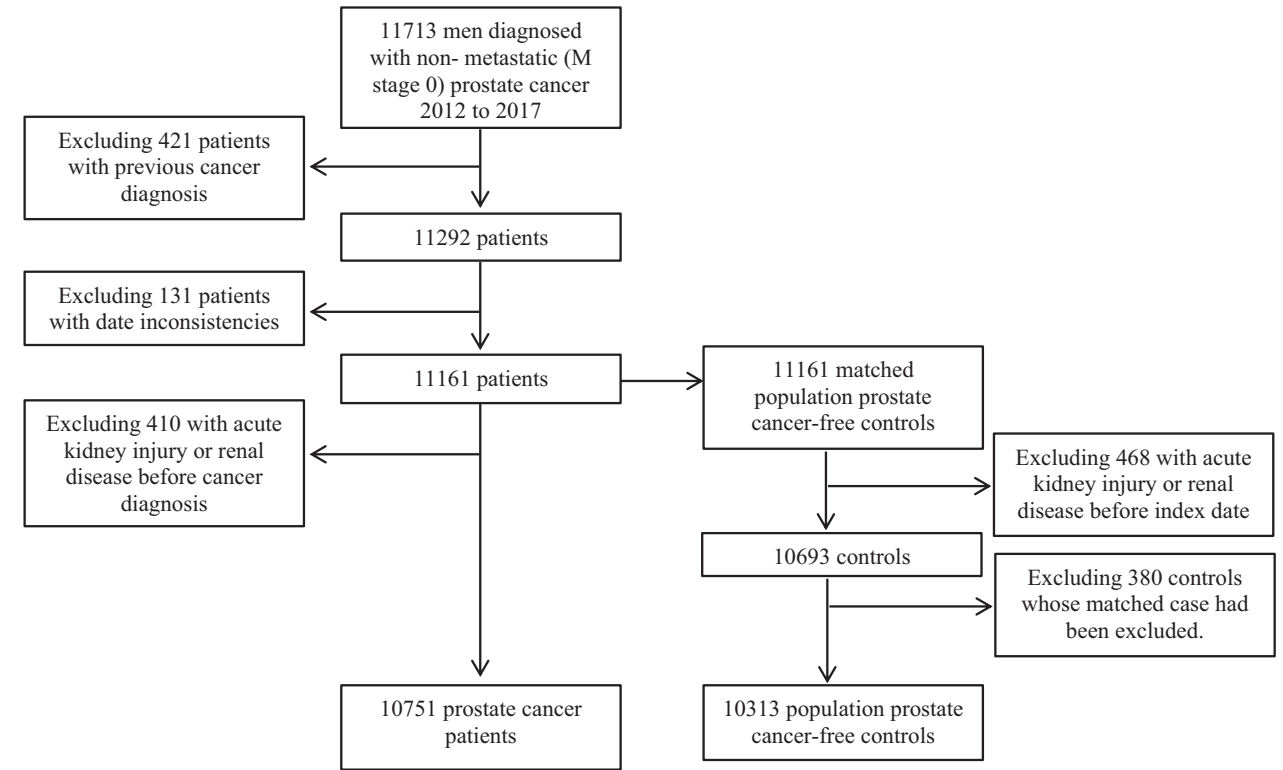

\section{Patient characteristics}

Hormone therapy users, compared with non-users, were older and had markedly higher $\mathrm{T}$ stage, $\mathrm{N}$ stage and Gleason score, higher rates of radiotherapy and lower rates of radical prostatectomy (see Table 1). Hormone therapy users also had slightly higher rates of comorbidities and medication use.

\section{Androgen deprivation therapy and acute kidney injury}

Table 2 shows that there was a marked increase in acute kidney injury with the current use of hormone therapy compared with no hormone therapy use ( $\mathrm{HR}=1.96,95 \%$ CI: $1.64,2.35)$. This was attenuated when adjusting for age (age-adjusted HR $=1.34,95 \% \mathrm{CI}: 1,12,1.61$ ) and when adjusting for age, year, deprivation, cancer treatment and comorbidities (adjusted $\mathrm{HR}=1.39,95 \% \mathrm{CI}$ : $1.14,1.68)$. After further adjustment for $\mathrm{T}$ stage and $\mathrm{N}$ stage, the association was attenuated further (fully adjusted $\mathrm{HR}=1.14,95 \% \mathrm{CI}: 0.92,1.41)$. There did not appear to be any association between past use of hormone therapy and acute kidney injury (fully adjusted $\mathrm{HR}=$ 1.02 , 95\% CI: $0.77,1.34)$. This pattern was similar for $\mathrm{GnRH}$ agonists and GnRH agonists and antagonists combined. However, there was an association between the current use of the GnRH antagonist degarelix and acute kidney injury before and after adjustments (unadjusted $\mathrm{HR}=4.60,95 \% \mathrm{CI}: 2.72,7.77$ and fully adjusted $\mathrm{HR}=$ $2.47,95 \%$ CI: $1.38,4.43)$.

\section{Sensitivity analyses}

Table 3 shows sensitivity analyses which in general gave similar results. In particular, associations were similar when restricting the acute kidney injury definition to the main condition within hospital records (current use fully adjusted $\mathrm{HR}=1.15,95 \% \mathrm{CI}: 0.69,1.90)$, when altering the duration of the residual effect including all prostate cancer patients (fully adjusted $\mathrm{HR}=1.03,95 \%$ CI: $0.88,1.21$ ). Censoring on radical prostatectomy and radiotherapy or not adjusting for radical prostatectomy and radiotherapy had little impact on the estimates. In patients with localised prostate cancer, a slighted more marked association was seen between current hormone therapy and acute kidney injury (unadjusted $\mathrm{HR}=2.23$, 95\% CI: $1.63,3.05$ ) which was only partly attenuated when adjusting for stage (adjusted $\mathrm{HR}=1.48$, 95\% CI: 1.06, 2.08), but was largely attenuated after further adjusting for Gleason score (unadjusted $\mathrm{HR}=1.23,95 \%$ CI: $0.83,1.82$ ).

Finally, a similar association was observed when any use of hormone therapy was investigated (unadjusted $\mathrm{HR}=$ $1.56,95 \%$ CI: $1.32,1.84$ and fully adjusted $\mathrm{HR}=1.11,95 \%$ CI: $0.91,1.36)$ or any use of GnRH agonists was investigated (unadjusted $\mathrm{HR}=1.49,95 \% \mathrm{CI}$ : $1.26,1.77$ and fully adjusted HR $=1.09,95 \%$ CI: $0.88,1.34)$. Patients using over 365 DDDs of androgen deprivation therapy, compared with non-users, had a more marked increase in acute kidney injury than patients using less than 365 DDDs, compared with non-users, before adjustments (unadjusted $\mathrm{HR}=1.21$, 95\% CI: $0.98,1.49$ and unadjusted $\mathrm{HR}=1.96,95 \% \mathrm{CI}$ : $1.62,2.38$, respectively). However, these associations were 
Table 1 Characteristics of prostate cancer patients by any use of hormone therapy.

\begin{tabular}{|c|c|c|}
\hline & \multicolumn{2}{|c|}{ Hormone therapy } \\
\hline & Non-users & Users $^{\mathrm{a}}$ \\
\hline \multicolumn{3}{|l|}{ Year of diagnosis } \\
\hline $2012-13$ & $1417(30 \%)$ & $1847(31 \%)$ \\
\hline $2014-15$ & $1526(32 \%)$ & $2071(35 \%)$ \\
\hline $2016-17$ & $1810(38 \%)$ & $2080(35 \%)$ \\
\hline \multicolumn{3}{|l|}{ Age at diagnosis } \\
\hline$<60$ & $986(21 \%)$ & $528(9 \%)$ \\
\hline $60-69$ & $2180(46 \%)$ & $2134(36 \%)$ \\
\hline $70-79$ & $1259(26 \%)$ & $2833(47 \%)$ \\
\hline 90 & $328(7 \%)$ & $503(8 \%)$ \\
\hline \multicolumn{3}{|l|}{ Deprivation } \\
\hline 1st fifth (least deprived) & $522(11 \%)$ & $829(14 \%)$ \\
\hline 2nd fifth & $818(17 \%)$ & $1055(18 \%)$ \\
\hline 3rd fifth & $969(20 \%)$ & $1269(21 \%)$ \\
\hline 4th fifth & $1115(23 \%)$ & $1425(24 \%)$ \\
\hline 5th fifth (most deprived) & $1307(27 \%)$ & $1407(23 \%)$ \\
\hline Radiotherapy (any time) & $711(15 \%)$ & $3912(65 \%)$ \\
\hline Radical prostatectomy (any time) & $1656(35 \%)$ & $297(5 \%)$ \\
\hline \multicolumn{3}{|l|}{ Hormone therapy during follow-up ${ }^{b}$} \\
\hline $\begin{array}{l}\text { GnNRH alone or with anti- } \\
\text { androgens }\end{array}$ & & $5303(88 \%)$ \\
\hline Degarelix alone & & $74(1 \%)$ \\
\hline Anti-androgens alone & & $506(8 \%)$ \\
\hline $\begin{array}{l}\text { Orchidectomy alone or with other } \\
\text { treatments }\end{array}$ & & $12(0 \%)$ \\
\hline $\begin{array}{l}\text { Estrogen alone or with other } \\
\text { treatments }\end{array}$ & & $9(0 \%)$ \\
\hline Other combinations & & $94(2 \%)$ \\
\hline \multicolumn{3}{|l|}{ Gleason score } \\
\hline$\leq 6$ & $2324(49 \%)$ & $746(12 \%)$ \\
\hline 7 & $1899(40 \%)$ & $2757(46 \%)$ \\
\hline 8 & $170(4 \%)$ & $765(13 \%)$ \\
\hline 9 & $109(2 \%)$ & $1259(21 \%)$ \\
\hline 10 & $5(0 \%)$ & $88(1 \%)$ \\
\hline Missing & $246(5 \%)$ & $383(6 \%)$ \\
\hline \multicolumn{3}{|l|}{$\mathrm{T}$ stage } \\
\hline 1 & $851(18 \%)$ & $309(5 \%)$ \\
\hline 2 & $2914(61 \%)$ & $2239(37 \%)$ \\
\hline 3 & $859(18 \%)$ & $2991(50 \%)$ \\
\hline 4 & $20(0 \%)$ & $281(5 \%)$ \\
\hline$X$ & $109(2 \%)$ & $178(3 \%)$ \\
\hline \multicolumn{3}{|l|}{$\mathrm{N}$ stage } \\
\hline 0 & $4438(93 \%)$ & $4929(82 \%)$ \\
\hline 1 & $55(1 \%)$ & $714(12 \%)$ \\
\hline $\mathrm{X}$ & $260(5 \%)$ & $355(6 \%)$ \\
\hline
\end{tabular}

Table 1 (continued)

\begin{tabular}{lcc}
\hline & \multicolumn{2}{c}{ Hormone therapy } \\
\cline { 2 - 3 } & Non-users & Users $^{\mathrm{a}}$ \\
\hline Selected mediations (in year before diagnosis) & \\
Aspirin & $857(18 \%)$ & $1484(25 \%)$ \\
ACE inhibitor & $1097(23 \%)$ & $1719(29 \%)$ \\
Statins & $1754(37 \%)$ & $2738(46 \%)$ \\
Tamsulosin & $1377(29 \%)$ & $1810(30 \%)$ \\
Selected comorbidities (in year before diagnosis) & \\
Myocardial infarction & $146(3 \%)$ & $325(5 \%)$ \\
Heart failure & $99(2 \%)$ & $191(3 \%)$ \\
Stroke & $132(3 \%)$ & $223(4 \%)$ \\
Diabetes & $193(4 \%)$ & $336(6 \%)$ \\
\hline
\end{tabular}

${ }^{\mathrm{a}}$ Hormone therapy at any time after diagnosis.

${ }^{\mathrm{b}}$ Treatments used at any time during entire follow-up period. Combinations of treatments not necessarily used simultaneously.

attenuated after adjustments (fully adjusted $\mathrm{HR}=1.02,95 \%$ CI: $0.81,1.28$ and fully adjusted $\mathrm{HR}=1.23,95 \%$ CI: 0.97 , 1.56 , respectively).

\section{Discussion}

In our study, patients with non-metastatic prostate cancer were at higher risk of hospitalisation with acute kidney injury compared with population-based controls. However, in prostate cancer patients, hormone therapy use and specifically GnRH agonist use was not associated with a higher risk of hospitalisation with acute kidney injury, after adjusting for confounders.

The only previous study to investigate acute kidney injury and current hormone therapy use [5] observed almost a $150 \%$ increase $(\mathrm{OR}=2.48,95 \%$ CI: $1.61,3.82)$ which is not consistent with our estimate of a $14 \%$ increase. The reason for the difference in findings is unclear but could partly reflect the time periods (they included cases diagnosed 1997-2009), differences in adjustments (they adjusted for smoking but not stage) or differences in the identification of prostate cancer patients.

A previous US study [6] investigating any use of $\mathrm{GnRH}$ agonists observed a comparatively small $24 \%$ increase in acute kidney injury risk $(\mathrm{HR}=1.24,95 \% \mathrm{CI}: 1.18,1.31)$. Notably, they did not investigate current use or a dose response, as data on the timing of androgen deprivation therapy were not available, and their study only included men over 66 years of age. In our analysis of ever use of GnRH agonists, we observed a non-significant 9\% increase $(\mathrm{HR}=1.09,95 \%$ CI: $0.88,1.34)$, but we cannot rule out small increases in risk based upon our CI. 
Table 2 Association between hormone therapy and acute kidney injury.

\begin{tabular}{|c|c|c|c|c|c|c|c|c|}
\hline & AKI cases & Person years & $\begin{array}{l}\text { Unadjusted HR } \\
(95 \% \mathrm{CI})\end{array}$ & $P$ & $\begin{array}{l}\text { Adjusted }^{\mathrm{a}} \mathrm{HR} \\
(95 \% \mathrm{CI})\end{array}$ & $P$ & $\begin{array}{l}\text { Fully adjusted }{ }^{\mathrm{b}} \mathrm{HR} \\
(95 \% \mathrm{CI})\end{array}$ & $P$ \\
\hline No hormone therapy use & 249 & 21196 & 1.00 (ref. cat.) & & 1.00 (ref. cat.) & & 1.00 (ref. cat.) & \\
\hline $\begin{array}{l}\text { Current hormone } \\
\text { therapy use }\end{array}$ & 253 & 11595 & $1.96(1.64,2.35)$ & $<0.001$ & $1.39(1.14,1.68)$ & 0.001 & $1.14(0.92,1.41)$ & 0.221 \\
\hline Past hormone therapy use & 116 & 9207 & $1.05(0.83,1.32)$ & 0.691 & $1.11(0.85,1.45)$ & 0.446 & $1.02(0.77,1.34)$ & 0.905 \\
\hline $\begin{array}{l}\text { GnRH agonist or } \\
\text { antagonist current }\end{array}$ & 236 & 10836 & $1.98(1.64,2.37)$ & $<0.001$ & $1.40(1.15,1.70)$ & 0.001 & $1.17(0.94,1.45)$ & 0.151 \\
\hline $\begin{array}{l}\text { GnRH agonist or } \\
\text { antagonist past }\end{array}$ & 101 & 8251 & $1.00(0.79,1.28)$ & 0.982 & $1.08(0.81,1.44)$ & 0.581 & $1.02(0.76,1.36)$ & 0.913 \\
\hline GnRH agonists current & 221 & 10588 & $1.90(1.58,2.29)$ & $<0.001$ & $1.35(1.11,1.65)$ & 0.003 & $1.13(0.90,1.40)$ & 0.289 \\
\hline GnRH agonists past & 97 & 8204 & $0.97(0.76,1.23)$ & 0.777 & $1.04(0.78,1.39)$ & 0.797 & $0.98(0.73,1.31)$ & 0.87 \\
\hline $\begin{array}{l}\text { GnRH antagonist } \\
\text { (degarelix) current }\end{array}$ & 15 & 267 & $4.60(2.72,7.77)$ & $<0.001$ & $2.83(1.62,4.94)$ & $<0.001$ & $2.47(1.38,4.43)$ & 0.002 \\
\hline $\begin{array}{l}\text { GnRH antagonist } \\
\text { (degarelix) past }\end{array}$ & 6 & 189 & $3.12(1.38,7.06)$ & 0.006 & $1.99(0.84,4.74)$ & 0.119 & $1.76(0.73,4.24)$ & 0.208 \\
\hline
\end{tabular}

$A K I$ acute kidney injury.

${ }^{a}$ Model contains: age, year, deprivation (in tenths), radiotherapy (as time-varying covariate), radical prostatectomy (as time-varying covariate), medications in the year prior to diagnosis (specifically: aspirin, beta-blockers, ACE inhibitors, ARBs, diuretics, statins, warfarin, digoxin, clopidogrel, dipyridamole, nitrates, insulin, sulfonylureas, metformin and other diabetic medications) and comorbidities prior to diagnosis (specifically: myocardial infarction, congestive heart failure, peripheral vascular disease, stroke, dementia, pulmonary disease, connective tissue disorder, paraplegia, peptic ulcer disease, liver disease, severe liver disease, diabetes and diabetes with complications).

${ }^{\mathrm{b}}$ Model contains all terms in 1 as well as $\mathrm{T}$ stage and $\mathrm{N}$ stage.

Overall, our findings do not appear to support the hypothesis that hormone therapy markedly increases the risk of acute kidney injury [5, 6] and should provide some reassurance to clinicians prescribing, and patients, taking androgen deprivation therapy. The observed increased risk of acute kidney injury with the GnRH antagonist degarelix is difficult to interpret as it was one of a number of analyses, based upon relatively few acute kidney injury events and because degarelix users are likely to have more advanced prostate cancer. Notwithstanding these caveats, this finding merits further research, particularly as this is the first investigation of this association.

Our study has various strengths. We assembled a large cohort of prostate cancer patients with detailed information on hormone therapy use and confounders including cancer stage. Acute kidney injury was ascertained from Scottish hospital records (SMR01), and although these records have been shown to have high accuracy for a range of conditions [12], misclassification is possible. The rate of acute kidney injury in our prostate cancer cohort (15 per 1000 person years) was higher than the previous UK study [5] (6 per 1000 person years) but lower than a US study [6] (27 per 1000 person years). The definition we used for acute kidney injury (of N17 as a main or secondary condition within hospital admissions data) has been previously validated with $95 \%$ of patients identified by this definition meeting Kidney Disease: Improving Global Outcomes criteria for acute kidney injury [14]. Furthermore, a separate analysis was conducted with acute kidney injury based solely on the main condition within hospital admissions data and similar findings were observed.

There is the possibility of residual confounding by incompletely recorded variables (e.g. Gleason score and $\mathrm{T}$ stage were $6 \%$ and $3 \%$ missing, respectively; and, the completeness of capture of certain treatments, for instance radiotherapy, is unclear) or unavailable variables (such as prostate-specific antigen, smoking, alcohol intake, ureteroscopy and nephrostomography). Also, data on prostate cancer progression during follow-up were not available, but this seems unlikely to explain our null results as patients who progress are more likely to receive hormone therapy and therefore may be at higher risk of acute kidney injury due to local invasion [6]. Hormone therapy use was determined from dispensing records but medication adherence cannot be confirmed. However, the limited evidence that exists suggest high adherence to oral androgen deprivation therapies [19]. Finally, patients receiving hormone therapies may have increased exposure to health care professionals increasing the likelihood of identifying acute kidney injury. 


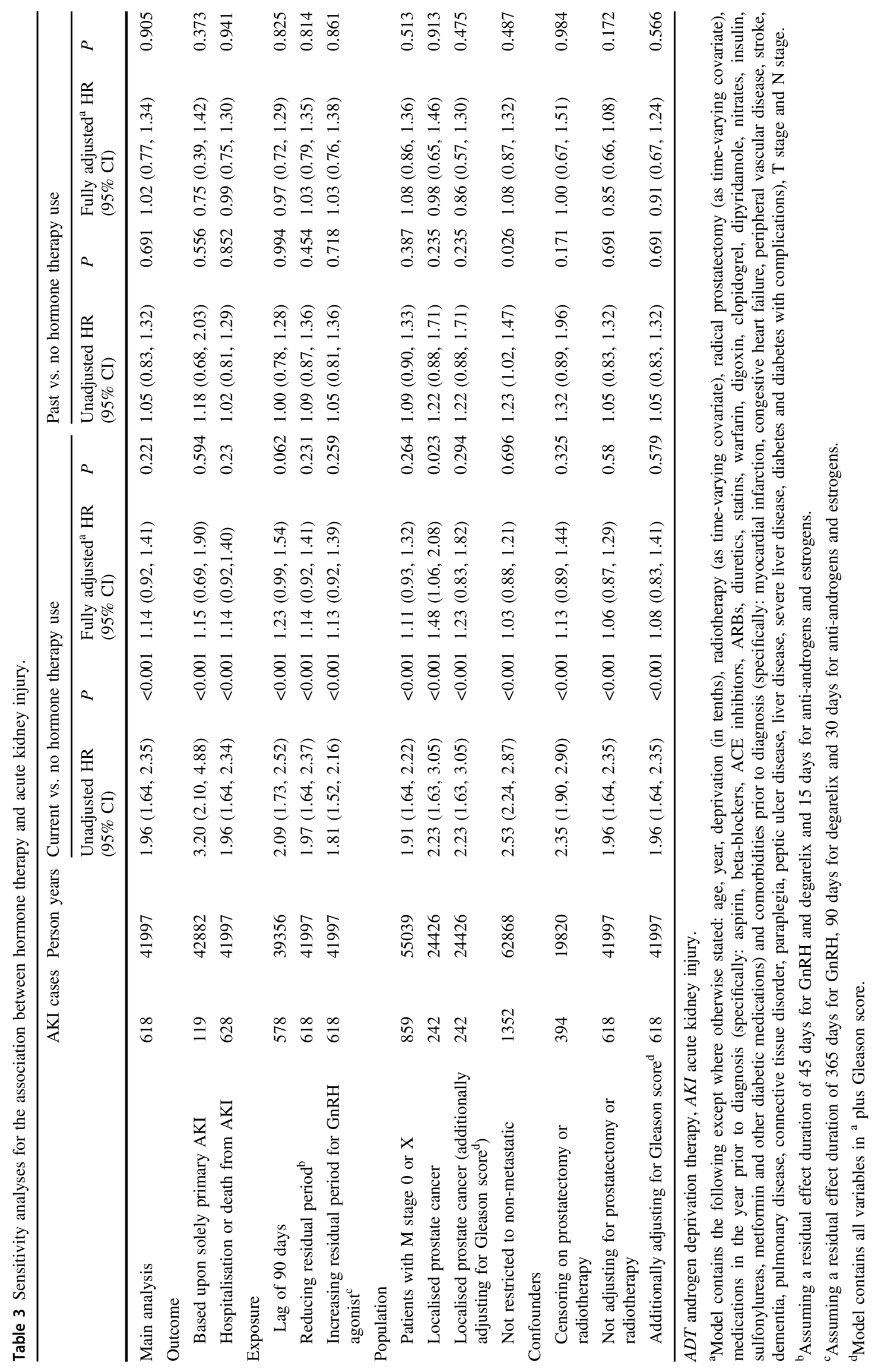




\section{Data availability}

Data were obtained and analysed, within a virtual safe haven, under strict licence conditions from the National Health Service National Services Scotland which do not permit data sharing. However, a researcher would be able to reconstruct these datasets and replicate these analyses after obtaining similar approvals from the National Health Services National Services Scotland.

Acknowledgements We thank the research coordinator (Lizzie Nicholson) and NHS National Services Scotland for facilitating data analysis.

Author contributions Study concept, design and acquisition of data: CRC and UCMM. Analysis and interpretation of data: CRC, JMO, SJ, BMH, PAD and UCMM. Drafting of the manuscript: CRC. Critical revision of the manuscript for important intellectual content: CRC, JMO, SJ, BMH, PAD and UCMM. Statistical analysis: CRC. Obtaining funding: CRC and UCMM.

Funding This work was supported by a Cancer Research UK Postdoctoral fellowship to UCMM [C53788/A20100] that provided access to the dataset. The sponsors had no involvement with the planning, execution, or completion of the study.

\section{Compliance with ethical standards}

Conflict of interest The authors declare no competing interests.

Ethics approval and consent to participate The study was approved by the Privacy Advisory Committee of the National Health Service (NHS) National Services Scotland (number: 1617-0374). All patient data were anonymous and therefore consent was not requested. The study was performed in accordance with the Declaration of Helsinki.

Publisher's note Springer Nature remains neutral with regard to jurisdictional claims in published maps and institutional affiliations.

Open Access This article is licensed under a Creative Commons Attribution 4.0 International License, which permits use, sharing, adaptation, distribution and reproduction in any medium or format, as long as you give appropriate credit to the original author(s) and the source, provide a link to the Creative Commons license, and indicate if changes were made. The images or other third party material in this article are included in the article's Creative Commons license, unless indicated otherwise in a credit line to the material. If material is not included in the article's Creative Commons license and your intended use is not permitted by statutory regulation or exceeds the permitted use, you will need to obtain permission directly from the copyright holder. To view a copy of this license, visit http://creativecommons. org/licenses/by/4.0/.

\section{References}

1. Cornford P, Bellmunt J, Bolla M, Briers E, De Santis M, Gross T, et al. EAU-ESTRO-SIOG Guidelines on Prostate Cancer. Part II: treatment of relapsing, metastatic, and castration-resistant prostate cancer. Eur Urol. 2017;71:630-42.
2. Jones CU, Hunt D, McGowan DG, Amin MB, Chetner MP, Bruner DW, et al. Radiotherapy and short-term androgen deprivation for localized prostate cancer. N. Engl J Med. 2011;365:107-18.

3. Mottet N, Bellmunt J, Bolla M, Briers E, Cumberbatch MG, De Santis $\mathrm{M}$, et al. EAU-ESTRO-SIOG Guidelines on Prostate Cancer. Part 1: screening, diagnosis, and local treatment with curative intent. Eur Urol. 2017;71:618-29.

4. Nguyen PL, Alibhai SM, Basaria S, D'Amico AV, Kantoff PW, Keating NL, et al. Adverse effects of androgen deprivation therapy and strategies to mitigate them. Eur Urol. 2015;67:825-36.

5. Lapi F, Azoulay L, Niazi MT, Yin H, Benayoun S, Suissa S. Androgen deprivation therapy and risk of acute kidney injury in patients with prostate cancer. JAMA. 2013;310:289-96.

6. Gandaglia G, Sun M, Hu JC, Novara G, Choueiri TK, Nguyen PL, et al. Gonadotropin-releasing hormone agonists and acute kidney injury in patients with prostate cancer. Eur Urol. 2014;66:1125-32.

7. Kambham N, Markowitz GS, Valeri AM, Lin J, D'Agati VD. Obesity-related glomerulopathy: an emerging epidemic. Kidney Int. 2001;59:1498-509.

8. Molinari C, Battaglia A, Grossini E, Mary DA, Vassanelli C, Vacca G. The effect of testosterone on regional blood flow in prepubertal anaesthetized pigs. J Physiol. 2002;543:365-72.

9. Mittalhenkle A, Stehman-Breen CO, Shlipak MG, Fried LF, Katz $\mathrm{R}$, Young BA, et al. Cardiovascular risk factors and incident acute renal failure in older adults: the cardiovascular health study. Clin J Am Soc Nephrol. 2008;3:450-6.

10. Rosner MH, Okusa MD. Acute kidney injury associated with cardiac surgery. Clin J Am Soc Nephrol. 2006;1:19-32.

11. Alvarez-Madrazo S, McTaggart S, Nangle C, Nicholson E, Bennie M. Data resource profile: The Scottish National Prescribing Information System (PIS). Int J Epidemiol. 2016;45:714-5f.

12. Information Service Division Scotland. Assessment of SMR01 Data 2010-2011. Scotland: Information Service Division; 2012. http://www.isdscotland.org/Health-Topics/Hospital-Care/Publica tions/2012-05-08/Assessment-of-SMR01Data-2010-2011-Scotla ndReport.pdf.

13. Sundararajan V, Henderson T, Perry C, Muggivan A, Quan H, Ghali WA. New ICD-10 version of the Charlson comorbidity index predicted in-hospital mortality. J Clin Epidemiol. 2004;57:1288-94.

14. Tomlinson LA, Riding AM, Payne RA, Abel GA, Tomson CR, Wilkinson IB, et al. The accuracy of diagnostic coding for acute kidney injury in England - a single centre study. BMC Nephrol. 2013;14:58.

15. World Health Organisation. World Health Organisation collaborating centre for drug statistics methodology. Oslo, Norway: World Health Organisation; 2021. https://www.whocc.no/atc/ structure_and_principles/.

16. Hussain S, Gunnell D, Donovan J, McPhail S, Hamdy F, Neal D, et al. Secular trends in prostate cancer mortality, incidence and treatment: England and Wales, 1975-2004. BJU Int. 2008;101:547-55.

17. The Scottish Government. Scottish index of multiple deprivation 2009: general report. Edinburgh, UK: Scottish Government; 2009.

18. Dekker FW, de Mutsert R, van Dijk PC, Zoccali C, Jager KJ. Survival analysis: time-dependent effects and time-varying risk factors. Kidney Int. 2008;74:994-7.

19. Grundmark B, Garmo H, Zethelius B, Stattin P, Lambe M, Holmberg L. Anti-androgen prescribing patterns, patient treatment adherence and influencing factors; results from the nationwide PCBaSe Sweden. Eur J Clin Pharm. 2012;68:1619-30. 